\title{
Effectiveness of Image-Guided Radiotherapy in Adjuvant Radiotherapy on Survival for Localized Breast Cancer: A Population-Based Analysis
}

\author{
Ji-An Liang ${ }^{1,2, *}$ \\ Po-Chang Lee ${ }^{3, *}$ \\ Chun-Ping $\mathrm{Ku}^{3, *}$ \\ William Tzu-Liang Chen ${ }^{2,3, *}$ \\ Chih-Yuan Chung ${ }^{4}$ \\ Yu-Cheng Kuo ${ }^{1,2}$ \\ Szu-Hsien Chou ${ }^{5}$ \\ Chia-Chin $\mathrm{Li}^{6}$ \\ Chun-Ru Chien ${ }^{1,2,6}$ \\ 'Department of Radiation Oncology, \\ China Medical University Hospital, \\ Taichung, Taiwan; ${ }^{2}$ School of Medicine, \\ College of Medicine, China Medical \\ University, Taichung, Taiwan; \\ ${ }^{3}$ Department of Surgery, China Medical \\ University Hsinchu Hospital, Hsinchu, \\ Taiwan; ${ }^{4}$ Department of Medical \\ Oncology, China Medical University \\ Hsinchu Hospital, Hsinchu, Taiwan; \\ ${ }^{5}$ Department of Medical Imaging, China \\ Medical University Hsinchu Hospital, \\ Hsinchu, Taiwan; ${ }^{6}$ Department of \\ Radiation Oncology, China Medical \\ University Hsinchu Hospital, Hsinchu, \\ Taiwan \\ *These authors contributed equally to \\ this work
}

Correspondence: Chun-Ru Chien

School of Medicine, College of Medicine, China Medical University, No. 9l HsuehShih Road, North District, Taichung, 40402, Taiwan

Tel +886-4-22052I $21-7450$

Fax +886-4-22052I $21-7460$

EmaildI6181@gmail.com
Purpose: Image-guided radiotherapy (IGRT) is an advanced radiotherapy technique to improve the radiotherapy delivery. We aimed to compare the overall survival (OS) for localized breast cancer (LBC) patient treated with adjuvant conventional fractionated radiotherapy (CFRT) using IGRT vs those without IGRT via a population-based analysis.

Patients and Methods: Eligible LBC patients diagnosed between 2011 and 2013 were identified via the Taiwan Cancer Registry. We used propensity score (PS) weighting to balance observable potential confounders between groups. The hazard ratio (HR) of death and other outcomes were compared between IGRT and non-IGRT. We also evaluated OS in various supplementary analyses.

Results: Our primary analysis included 6490 patients in whom covariates were well balanced after PS weighing. The HR for death when IGRT was compared with non-IGRT was $1.02(95 \%$ confidence interval $0.80-1.31, \mathrm{P}=0.86)$. There were also no significant differences in the supplementary analyses.

Conclusion: We found that OS of LBC patients treated with adjuvant CFRT was not statistically different between those treated with IGRT versus without IGRT. This was the first study in this regard to our knowledge but randomized controlled trials were needed to confirm our finding.

Keywords: breast cancer, effectiveness, image-guided radiotherapy

\section{Introduction}

Breast cancer is one of the leading causes of cancer mortality around the world including Taiwan. ${ }^{1}$ Adjuvant radiotherapy (RT) is commonly used for localized breast cancer after breast-conserving surgery (BCS) or mastectomy ${ }^{2}$ and can improve local control as well as overall survival. ${ }^{3}$

Image-guided radiotherapy (IGRT) is a strategy using various devices to improve the quality of treatment execution with the potential to improve outcomes. ${ }^{4-6}$ In general, IGRT was recommended in the textbook ${ }^{6}$ or radiotherapy guideline $^{7}$ although its role in breast cancer radiotherapy was less clear and stated as "routine use of daily imaging is not recommended" in the national comprehensive cancer network (NCCN) guideline. ${ }^{2}$ IGRT was also usually highly preferred in the setting of radiosurgery or hypofractionated regimens. ${ }^{5}$

However, a randomized controlled trial (RCT) of conventional fractionated radiotherapy (CFRT) for definitive prostate radiotherapy was published in 2018 and reported significantly worse overall survival (OS) for those treated with IGRT. ${ }^{8}$ Theoretically, the 
extra-radiotherapy dose due to xray-IGRT may have contributed to the increased risk of other cancer $(10 \%$ vs $5 \%)$ or cardiovascular mortality (6/236 vs $1 / 234)$ observed in this study and led to the impaired overall survival. ${ }^{8}$ It raised the concern regarding the effectiveness of IGRT in other cancers such as in breast cancer. However, there was no published RCT regarding IGRT's impact on OS for breast cancer to our knowledge. ${ }^{9}$ Therefore, the aim of this comparativeness effectiveness research is to investigate the effectiveness of Imageguided radiotherapy in adjuvant conventional fractionated radiotherapy for localized breast cancer patients via a population-based analysis.

\section{Patients and Methods \\ Data Source}

In this retrospective cohort study, the analyzed data with personal identifiers removed were obtained from Health and Welfare Data Science Center (HWDC) database, which included the Taiwan cancer registry (TCR), death registration, and reimbursement data for the whole Taiwan population provided by the Bureau of National Health Insurance (NHI). The TCR is a high-quality database ${ }^{10}$ that provides comprehensive information such as patient, disease, and treatment characteristics, and prognostic factor details. This study was approved by the research ethics committee at our institute (CRREC-108-080 by Central Regional Research Ethics Committee China Medical University which waived the requirement to obtain consent from the study participants prior to study commencement).

\section{Study Population and Study Design}

The study flowchart as suggested in the STROBE statement ${ }^{11}$ was depicted in Figure 1. Our study population consisted of female localized breast cancer patients diagnosed within 2011-2013 who received adjuvant radiotherapy after R0 resection, with external beam radiotherapy using conventional fractionation via image-guided radiotherapy (IGRT) or non-IGRT. We selected this time frame to ensure at least 5 years window for survival measurement. We limited to CFRT instead of hypofractionated radiotherapy (HFRT) because CFRT was recommend for all three scenarios in our study whereas HFRT was not recommended for post-mastectomy chest wall radiotherapy or nodal irradiation. ${ }^{2}$ In addition, IGRT was recommended for extreme HFRT in a previous study. ${ }^{12}$ The three treatment scenarios included in our study were (A) BCS followed by RT; (B) mastectomy followed by RT; (C) neoadjuvant systemic therapy followed by surgery (BCS or mastectomy) followed by RT. We only included those age within 18-70 years old and excluded those with bilateral breast cancer or previous other cancer. These inclusion/exclusion criteria were based on the clinical trial, treatment guideline, and our clinical experiences. ${ }^{2,12}$

The explanatory variable of interest [IGRT vs nonIGRT], the primary outcome of interest [overall survival (OS)] and other supplementary outcomes [incidence of breast cancer mortality (IBCM), other cancer mortality (IOCM) and cardiovascular mortality (ICVM)] were determined via the recordings in TCR or the death registry. We adopted OS as the primary outcome of interest because OS was obviously the most important outcome and the negative OS reported in the previous IGRT RCT. ${ }^{8}$ We defined the date of diagnosis as the index date and calculated the OS or other endpoints from the index date to the date of death or Dec 31, 2018 [the censoring date of death registry]. We also collected covariates from TCR and reimbursement data to adjust for potential nonrandomized treatment selection [see section "Other explanatory covariates" in Supplementary Material]. The covariates were modified from the literature ${ }^{12}$ as well as our experiences in clinical care ${ }^{13}$ and TCR studies. ${ }^{14,15}$

\section{Statistical and Supplementary Analyses}

In the primary analysis (PA), we adopted the propensityscore (PS) method with a logistic regression model based on the above covariates to balance the measured potential confounders. ${ }^{16-18} \mathrm{We}$ evaluated the probability of receiving IGRT (vs non-IGRT) and then assessed the balance of covariates between groups (IGRT vs non-IGRT) with the standardized difference. ${ }^{13,19}$ During the entire follow-up period, we used the overlap weights ${ }^{20,21}$ via a PS weighting approach to compare the hazard ratio (HR) of death between IGRT and non-IGRT groups. The cox proportional hazards model in the weighted sample was used for point estimation, and the bootstrap method was used to estimate the $95 \%$ confidence interval $(95 \% \mathrm{CI}){ }^{20,22,23}$ We also compare IBCM, IOCM, and ICVM between groups using the competing risk approach. ${ }^{24}$

In the first to fourth supplementary analyses (SA), we adopted PS matching to construct 1:1 PS matched cohort for four subgroups separately and compared the HR of death between IGRT and non-IGRT groups via a robust variance estimator. ${ }^{20}$ In the first supplementary analysis (SA-1), we performed PS matching among the study population of the primary analysis. We also did additional SA (SA-2 - SA-4) 
for those received BCS \& breast RT (SA-2), BCS \& breast plus nodal RT (SA-3), and mastectomy and chest wall plus nodal RT (SA-4). We selected these three SA (SA-2 - SA-4) because these were the three common volumes used for breast cancer radiotherapy. ${ }^{25-27}$ In the 5 th $\mathrm{SA}$, we used alternative covariate classification $[\mathrm{T} 1, \mathrm{~T} 2, \mathrm{~T} 3, \mathrm{~T} 4$ for T-stage and N0, N1, N2, N3 for N-stage] in the PS weighting analyses as suggested during revision. The statistical analyses were performed using the software SAS 9.4 (SAS Institute, Cary, NC).

\section{Results}

\section{Study Population in the Primary Analysis}

Among 6490 eligible localized breast cancer females received IGRT or non-IGRT between 2011 and 2013 were identified, 1013 patients were treated with IGRT whereas 5477 were treated without IGRT (Figure 1). The patient characteristics are described in Table 1. One covariate [residency] was not balanced before weighting analysis, but all covariates were balanced (standardized differences $<0.25$ ) after PS weighting via overlap weights.

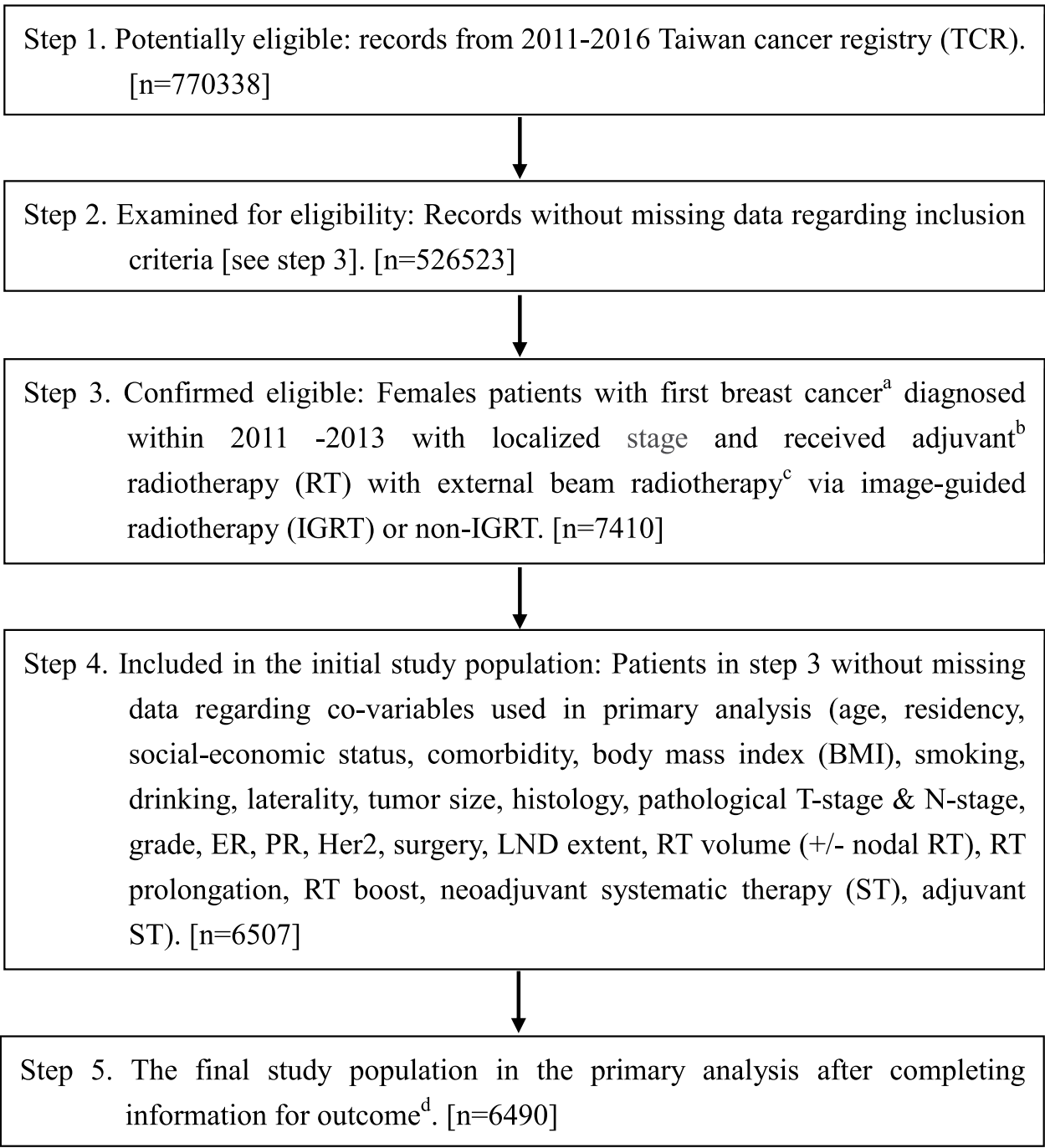

Figure I STROBE study flowchart and the number of individuals at each stage of the study.

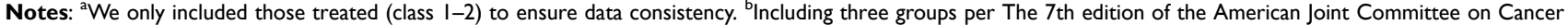
staging: (group A) clinical stageT0-3N0-IMO and pathological staging TI-4N0-3 treated with breast-conserving surgery (BCS); (group B) clinical stage T0-3N0-IMO and pathological staging TI-4NI-3 treated with mastectomy; (group C) clinical stage T2-4N0-3M0 or TI-4NI-3M0, and pathological staging T0-4N0-3 treated with either BCS or mastectomy. ${ }^{\mathrm{C}} 45-66.4 \mathrm{~Gy}$ in $1.8-2 \mathrm{~Gy} /$ fraction, within $\pm 10 \%$ in dose and treatment duration. ${ }^{\mathrm{d}}$ Without missing information in the TCR and death registry regarding survival status, and cause of death.

Abbreviations: ER, estrogen receptor; Her2, human epidermal growth factor receptor 2; LND, lymph node dissection, expressed as number of pathologically examined lymph nodes; PR, progesterone receptor. 
Table I Patient Characteristics of the Study Population in the Primary Analysis

\begin{tabular}{|c|c|c|c|c|c|c|c|}
\hline & & \multirow{2}{*}{$\frac{\text { IGRT }(n=10 \mid 3)}{\text { Number or Mean }(s d)^{a}}$} & \multirow[b]{2}{*}{$(\%)^{a}$} & \multirow{2}{*}{$\begin{array}{l}\text { Non-IGRT }(n=5477) \\
\text { Number or Mean }(s d)^{a}\end{array}$} & \multirow[b]{2}{*}{$(\%)^{a}$} & \multicolumn{2}{|c|}{ Standardized Difference ${ }^{a}$} \\
\hline & & & & & & Before PSW & After PSW \\
\hline Age (years) & & $50.17(9.11)$ & & $50.77(9.35)$ & & 0.065 & $\approx 0$ \\
\hline \multirow[t]{2}{*}{ Residency } & Non-north & 762 & 75 & 2485 & 45 & \multirow[t]{2}{*}{0.641} & \multirow[t]{2}{*}{$\approx 0$} \\
\hline & North & 251 & 25 & 2992 & 55 & & \\
\hline \multirow[t]{2}{*}{ Social economic status } & No more than minimum wage & 215 & 21 & 1224 & 22 & \multirow[t]{2}{*}{0.027} & \multirow[t]{2}{*}{$\approx 0$} \\
\hline & Higher & 798 & 79 & 4253 & 78 & & \\
\hline \multirow[t]{2}{*}{ Comorbidity } & Without & 730 & 72 & 3940 & 72 & \multirow[t]{2}{*}{0.003} & \multirow[t]{2}{*}{$\approx 0$} \\
\hline & With $^{\mathrm{b}}$ & 283 & 28 & 1537 & 28 & & \\
\hline BMI & & $24.19(4.10)$ & & $24.41(4.24)$ & & 0.052 & 0 \\
\hline \multirow[t]{2}{*}{ Smoking } & No & 964 & 95 & 5195 & 95 & \multirow[t]{2}{*}{0.014} & \multirow[t]{2}{*}{$\approx 0$} \\
\hline & Yes & 49 & 5 & 282 & 5 & & \\
\hline \multirow[t]{2}{*}{ Drinking } & No & 979 & 97 & 5091 & 93 & \multirow[t]{2}{*}{0.167} & \multirow[t]{2}{*}{$\approx 0$} \\
\hline & Yes & 34 & 3 & 386 & 7 & & \\
\hline \multirow[t]{2}{*}{ Laterality } & Left & 508 & 50 & 2804 & 51 & \multirow[t]{2}{*}{0.021} & \multirow[t]{2}{*}{0} \\
\hline & Right & 505 & 50 & 2673 & 49 & & \\
\hline Tumor size $(\mathrm{mm})$ & & $24.20(16.66)$ & & $24.32(16.95)$ & & 0.007 & 0 \\
\hline \multirow[t]{2}{*}{ Histology } & IDC & 886 & 87 & 4763 & 87 & 0.015 & 0 \\
\hline & Others & 127 & 13 & 714 & 13 & & \\
\hline pT & $1-2$ & 951 & 94 & 5178 & 95 & 0.028 & 0 \\
\hline & $3-4$ & 62 & 6 & 299 & 5 & & \\
\hline $\mathrm{pN}$ & $0-1$ & 816 & 81 & 4329 & 79 & 0.038 & 0 \\
\hline & $2-3$ & 197 & 19 & 1148 & 21 & & \\
\hline Grade & Low & 701 & 69 & 3675 & 67 & 0.045 & $\approx 0$ \\
\hline & High & 312 & 31 & 1802 & 33 & & \\
\hline ER & No & 184 & 18 & 1051 & 19 & 0.026 & 0 \\
\hline & Yes & 829 & 82 & 4426 & 81 & & \\
\hline PR & No & 268 & 26 & 1463 & 27 & 0.006 & 0 \\
\hline & Yes & 745 & 74 & 4014 & 73 & & \\
\hline Her2 & No & 767 & 76 & 4159 & 76 & 0.005 & 0 \\
\hline & Yes & 246 & 24 & 1318 & 24 & & \\
\hline Surgery & Mastectomy & 280 & 28 & 1751 & 32 & 0.095 & 0 \\
\hline & $\mathrm{BCS}$ & 733 & 72 & 3726 & 68 & & \\
\hline LND extent (number) & & $10.82(9.21)$ & & $12.34(10.43)$ & & 0.155 & $\approx 0$ \\
\hline RT volume & Without & 499 & 49 & 2659 & 49 & 0.014 & $\approx 0$ \\
\hline & With nodal RT & 514 & 51 & 2818 & 51 & & \\
\hline $\mathrm{RT}$ prolongation & $\leq \mathrm{I}$ week & 943 & 93 & 5224 & 95 & 0.098 & 0 \\
\hline & > I week & 70 & 7 & 253 & 5 & & \\
\hline RT boost & No & 274 & 27 & 1393 & 25 & 0.037 & $\approx 0$ \\
\hline & Yes & 739 & 73 & 4084 & 75 & & \\
\hline Neoadjuvant ST & No & 907 & 90 & 4866 & 89 & 0.022 & $\approx 0$ \\
\hline & Yes & 106 & 10 & 611 & 11 & & \\
\hline
\end{tabular}

(Continued) 
Table I (Continued).

\begin{tabular}{|c|c|c|c|c|c|c|c|}
\hline & & \multirow{2}{*}{$\frac{\text { IGRT }(n=|0| 3)}{\text { Number or Mean }(s d)^{a}}$} & \multirow[b]{2}{*}{$(\%)^{a}$} & \multirow{2}{*}{$\begin{array}{c}\text { Non-IGRT (n=5477) } \\
\text { Number or Mean (sd) }\end{array}$} & \multirow[b]{2}{*}{$(\%)^{a}$} & \multicolumn{2}{|c|}{ Standardized Difference ${ }^{a}$} \\
\hline & & & & & & Before PSW & After PSW \\
\hline \multirow[t]{2}{*}{ Adjuvant ST } & No & 21 & 2 & 129 & 2 & 0.019 & 0 \\
\hline & Yes & 992 & 98 & 5348 & 98 & & \\
\hline
\end{tabular}

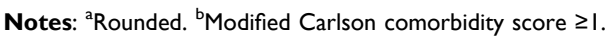

Abbreviations: BCS, breast-conserving surgery; BMI, body mass index; ER, estrogen receptor; IDC, infiltrating ductal carcinoma; Her2, human epidermal growth factor receptor 2; IGRT, image-guided radiotherapy; LND, lymph node dissection; PSW, propensity-score weighting; PR, progesterone receptor; RT, radiotherapy; sd, standard deviation; ST, systemic treatment.

\section{Primary Analysis}

After a median follow-up of 76 months [range 5-96 months], death was observed for 74 patients in the IGRT group and 401 patients in the non-IGRT group. The overlap weights adjusted OS curve was shown in Figure 2. The 5 -year OS rates for two groups were $94.35 \%$ [IGRT] and 94.64\% [non-IGRT]. The PS weighting adjusted HR of death when IGRT was compared to non-IGRT was 1.02 [ $95 \%$ confidence interval $(95 \% \mathrm{CI}) 0.80-1.31, \mathrm{P}=0.86$ ] The results were also not significantly different for IBCM
$[\mathrm{HR}=1.02, \mathrm{P}=0.94], \mathrm{IOCM}[\mathrm{HR}=1.43, \mathrm{P}=0.51]$ and $\operatorname{ICVM}[\mathrm{HR}=0.65, \mathrm{P}=0.66]$.

\section{Supplementary Analyses (SA)}

In the SA-1 to SA-4, covariates were also balanced after PS matching [Table S1-S4]. There were also no statistically significant difference for OS when IGRT was compared to non-IGRT [SA-1: $\mathrm{HR}=1.08, \mathrm{P}=0.64$; $\mathrm{SA}-2$ : $\mathrm{HR}=0.57, \mathrm{P}=$ 0.09; $\mathrm{SA}-3$ : $\mathrm{HR}=1.04, \mathrm{P}=0.91$; $\mathrm{SA}-4: \mathrm{HR}=1.07, \mathrm{P}=0.77$ ]. In SA-5 when alternative covariate classification was used,

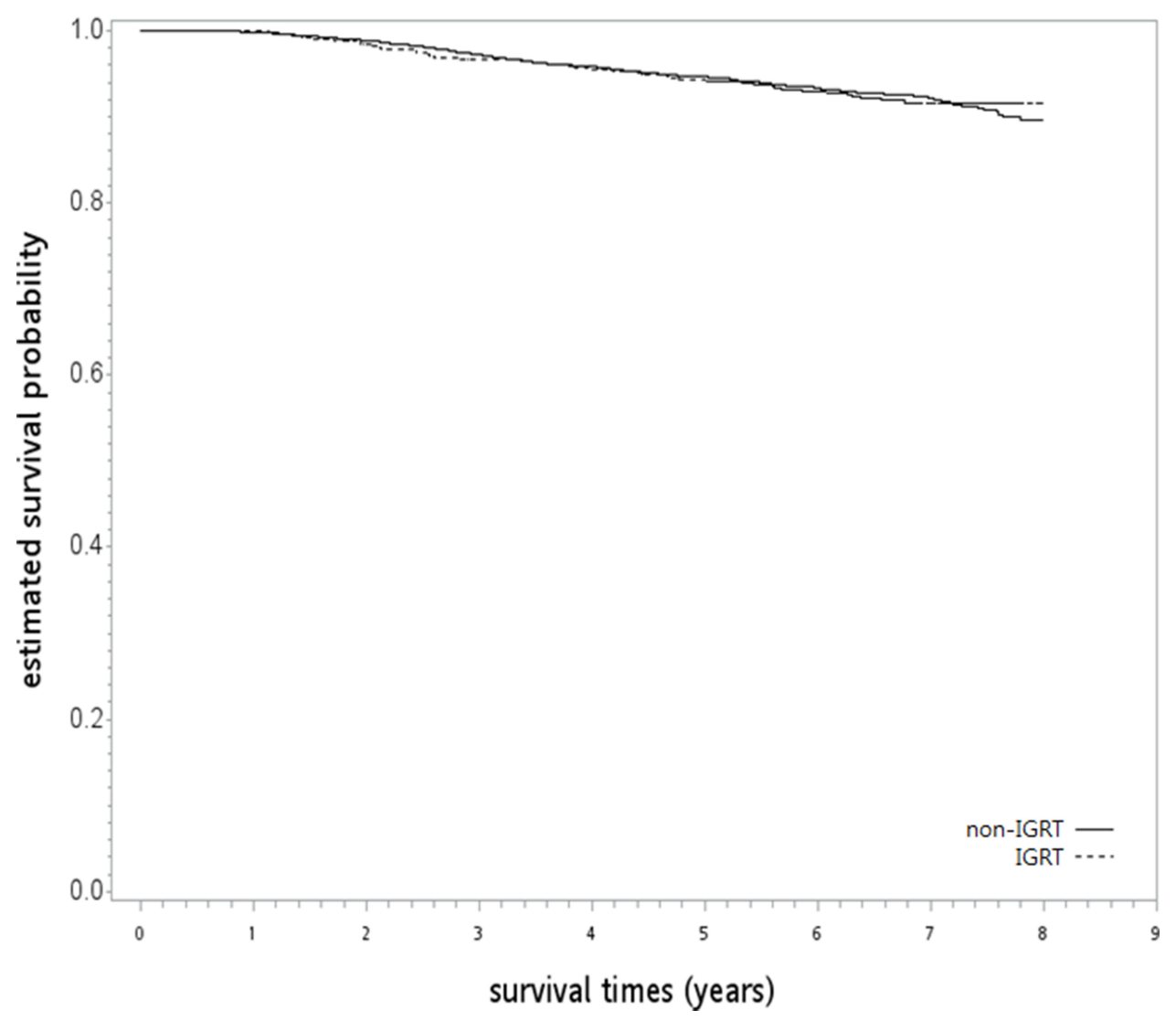

Figure 2 The overlap weights adjusted overall survival curve (in years) in the primary analysis. 
covariates were balanced after PS weighting [Table S5] and similar results were seen $[\mathrm{HR}=1.01, \mathrm{P}=0.95]$.

\section{Discussion}

In this population-based analysis, we found that the use of image-guided radiotherapy in adjuvant conventional fractionated radiotherapy for localized breast cancer patients did not lead to worse overall survival or other outcomes. This was the first study in this regard to our knowledge.

As we mentioned in the above introduction section, IGRT was advocated in the field of breast radiation oncology in general ${ }^{4,28,29}$ but not recommended by the current NCCN guideline. ${ }^{2}$ One study for 174 breast cancer patients treated with adjuvant whole breast CFRT after BCS had stated "Extensive set-up errors were found in more than half patients undergoing conventional fractionated radiotherapy and IGRT was advocated for these patients". ${ }^{30}$ However, when we searched in Pubmed using “((IGRT) OR (Image-guided Radiation Therapy) OR ((image*) AND (guid*) AND ((radiotherapy) OR (radiation therapy)))) AND survival AND (breast cancer)" in Dec 2020, we did not found studies comparing survival outcomes of breast adjuvant CFRT via IGRT vs non-IGRT, although IGRT was advocated in some HFRT studies. ${ }^{31,32}$

The motivation of our study was the negative survival impact of IGRT on prostate cancer radiotherapy along with the higher risk of secondary cancer and cardiovascular mortality reported in the recent $\mathrm{RCT}^{8}{ }^{8}$ Our results revealed that IGRT in adjuvant CFRT for localized breast cancer patients did not lead to worse overall survival or other outcomes. So it might be safe to use IGRT (usually via $\mathrm{x}$-ray) regardless of the theoretical concern in cardiovascular disease or secondary cancer, ${ }^{33,34}$ at least for selected patients with significant setup errors. However, it should be noted the radiotherapy setting and technique in prostate cancer radiotherapy in that $\mathrm{RCT}^{8}$ was different vs the one for breast cancer in the current study [curative/definitive vs preventive/adjuvant]. Furthermore, our results should also be interpreted with caution given its non-randomized nature. However, there was no published RCT to our knowledge. ${ }^{9}$ We further searched in clinical trials registry [https://clinicaltrials.gov/] in Dec 2020 using keywords "(image-guided radiation therapy) OR (image-guided radiotherapy) OR (IGRT) | breast cancer" but did not find ongoing RCT as well. Therefore, our study would be a reasonable tentative evidence to guide the use of IGRT for breast cancer patients treated with adjuvant CFRT, whereas the role of IGRT in HFRT deserves further study.

There were some limitations of our study to be addressed below. Firstly, the treatment [IGRT] was not randomly given so the impact of potentially unobserved confounders could not be eliminated although we had used PS methods to adjust for observable ones. Furthermore, the treatment [IGRT] in our study was not homogeneous but the detail could not be clarified with certain due to data limitation in HWDC. Secondly, the minimal potential follow-up in our study [5 year] may not be long enough to capture some long term effects which had been reported in some HFRT studies. ${ }^{35}$ Thirdly, other potential covariables [such as systemic therapy details] or outcomes [such as patient reported outcome or quality of life] might also be relevant but were not investigated in our study due to data limitation.

\section{Conclusion}

Our non-randomized population-based study found that the overall survival of localized breast cancer patients treated with adjuvant CFRT was not statistically different between those treated with IGRT versus without IGRT. This was the first study in this regard to our knowledge but randomized controlled trials were needed to confirm our finding.

\section{Acknowledgments}

The data analyzed in this study were provided by the Health and Welfare Data Science Center, Ministry of Health and Welfare, Taiwan. The corresponding author would like to thank Liang JA, Lee PC, Ku CP, and Chen WTL for their equal contribution to this work. We are grateful to the Health Data Science Center at the China Medical University Hospital and China Medical University Hsinchu Hospital [CMUHCH-DMR-110-002 \& CMUHCH-DMR-110-015] and the Ministry of Science and Technology[MOST 1092314-B-039-014-] for providing administrative, technical and funding support.

\section{Disclosure}

Dr Ji-An Liang reports grants from China Medical University Hsinchu Hospital, during the conduct of the study. Dr PoChang Lee reports grants from China Medical University Hsinchu Hospital, during the conduct of the study. Dr Chun$\mathrm{Ru}$ Chien reports grants from the Ministry of Science and Technology, grants and non-financial support from China Medical University Hsinchu Hospital, and non-financial 
support from the Health Data Science Center at the China Medical University Hospital, during the conduct of the study. The authors declare that there are no other conflicts of interest.

\section{References}

1. Bray F, Ferlay J, Soerjomataram I, Siegel RL, Torre LA, Jemal A. Global cancer statistics 2018: GLOBOCAN estimates of incidence and mortality worldwide for 36 cancers in 185 countries. $C A$ Cancer J Clin. 2018;68:394-424. doi:10.3322/caac.21492

2. National Comprehensive Cancer Network. Guidelines for breast cancer, version 6; 2020. Available from: https://www.nccn.org/profes sionals/physician_gls/pdf/breast.pdf. [free registration required] Accessed November 28, 2020.

3. Clarke M, Collins R, Darby S, et al. Effects of radiotherapy and of differences in the extent of surgery for early breast cancer on local recurrence and 15-year survival: an overview of the randomised trials. Lancet. 2005;366:2087-2106.

4. Leonardi MC, Ricotti R, Dicuonzo S, et al. From technological advances to biological understanding: the main steps toward high-precision RT in breast cancer. Breast. 2016;29:213-222. doi:10.1016/j.breast.2016.07.010

5. Bujold A, Craig T, Jaffray D, Dawson LA. Image-guided radiotherapy: has it influenced patient outcomes? Semin Radiat Oncol. 2012;22:50-61. doi:10.1016/j.semradonc.2011.09.001

6. Simpson DR, Mell LK, Mundt AJ, et al. Image guided radiation therapy. In: Halperin EC, Wazer DE, Perez CA, Brady LW, editors. Perez \& Brady's Principles and Practice of Radiation Oncology, 7th ed. Philadelphia: Wolters Kluwer; 2018:288-307.

7. Ghadjar P, Fiorino C, Munck Af Rosenschöld P, et al. ESTRO ACROP consensus guideline on the use of image guided radiation therapy for localized prostate cancer. Radiother Oncol. 2019;141:5-13. doi:10.1016/j.radonc.2019.08.027

8. de Crevoisier R, Bayar MA, Pommier P, et al. Daily versus weekly prostate cancer image guided radiation therapy: phase 3 multicenter randomized trial. Int J Radiat Oncol Biol Phys. 2018;102:1420-1429. doi:10.1016/j.ijrobp.2018.07.2006

9. Chou SH, Li YH, Juan CJ, Juan CJ, Li CC, Chien CR. The effect of image-guided radiotherapy on cancer patients' survival. Value Health Reg Issues. 2020;22(Supp):S4. doi:10.1016/j.vhri.2020.07.052

10. Chiang CJ, Wang YW, Lee WC. Taiwan's nationwide cancer registry system of 40 years: past, present, and future. J Formos Med Assoc. 2019;118:856-858. doi:10.1016/j.jfma.2019.01.012

11. von Elm E, Altman DG, Egger M, et al. The Strengthening the Reporting of Observational Studies in Epidemiology (STROBE) statement: guidelines for reporting observational studies. Lancet. 2007;370:1453-1457. doi:10.1016/S0140-6736(07)61602-X

12. Brunt AM, Haviland JS, Wheatley DA, et al. Hypofractionated breast radiotherapy for 1 week versus 3 weeks (FAST-Forward): 5-year efficacy and late normal tissue effects results from a multicentre, non-inferiority, randomised, phase 3 trial. Lancet. 2020;395:1613-1626. doi:10.1016/S0140-6736(20)30932-6

13. Ali MS, Groenwold RH, Belitser SV, et al. Reporting of covariate selection and balance assessment in propensity score analysis is suboptimal: a systematic review. $J$ Clin Epidemiol. 2015;68:112-121. doi:10.1016/j.jclinepi.2014.08.011

14. Liang JA, Tu CY, Hsia TC, Fang HY, Li CC, Chien CR. Effectiveness of image-guided radiotherapy for locally advanced lung cancer patients treated with definitive concurrent chemoradiotherapy. Thorac Cancer. 2020;11:2639-2649. doi:10.1111/1759-7714.13596

15. Kuo YH, Fang HY, Lin YS, et al. Effectiveness of image-guided radiotherapy for locally advanced esophageal squamous cell carcinoma patients treated with definitive concurrent chemoradiotherapy. Thorac Cancer. 2020;11:113-119. doi:10.1111/1759-7714.13244
16. Lalani N, Jimenez RB, Yeap B. Understanding propensity score analyses. Int $J$ Radiat Oncol Biol Phys. 2020;107:404-407. doi:10.1016/j.ijrobp.2020.02.638

17. Rosenbaum PR. Chapter 5 between observational studies and experiments. In: Rosenbaum PR, editor. Observation and Experiment. Cambridge, Massachusetts: Harvard University Press; 2017.

18. Booth CM, Karim S, Mackillop WJ. Real-world data: towards achieving the achievable in cancer care. Nat Rev Clin Oncol. 2019;16:312-325. doi:10.1038/s41571-019-0167-7

19. Garrido MM, Kelley AS, Paris J, et al. Methods for constructing and assessing propensity scores. Health Serv Res. 2014;49:1701-1720. doi:10.1111/1475-6773.12182

20. Austin PC. The use of propensity score methods with survival or time-to-event outcomes: reporting measures of effect similar to those used in randomized experiments. Stat Med. 2014;33:1242-1258. doi:10.1002/sim.5984

21. Mao H, Li L, Greene T. Propensity score weighting analysis and treatment effect discovery. Stat Methods Med Res. 2019;28:2439-2454. doi:10.1177/0962280218781171

22. Cole SR, Hernán MA. Adjusted survival curves with inverse probability weights. Comput Methods Programs Biomed. 2004;75:45-49. doi:10.1016/j.cmpb.2003.10.004

23. Austin PC. Variance estimation when using inverse probability of treatment weighting (IPTW) with survival analysis. Stat Med. 2016;35:5642-5655. doi:10.1002/sim.7084

24. Bolch CA, Chu H, Jarosek S, Cole SR, Elliott S, Virnig B. Inverse probability of treatment-weighted competing risks analysis: an application on long-term risk of urinary adverse events after prostate cancer treatments. BMC Med Res Methodol. 2017;17:93. doi:10.1186/s12874017-0367-8

25. Loganadane G, Truong PT, Taghian AG, et al. Comparison of nodal target volume definition in breast cancer radiation therapy according to RTOG versus ESTRO atlases: a practical review from the TransAtlantic Radiation Oncology Network (TRONE). Int J Radiat Oncol Biol Phys. 2020;107:437-448. doi:10.1016/j.ijrobp.2020.04.012

26. Breast cancer atlas for Radiation Therapy Planning: Consensus Definitions. Available from: https:/www.nrgoncology.org/Portals/0/ Scientific\%20Program/CIRO/Atlases/BreastCancerAtlas_corr.pdf? ver=2018-04-18-144201-270\&ver=2018-04-18-144201-270. Accessed April 1 ${ }^{\text {st }}, 2021$.

27. Lan XW, Wen G, He Z, et al. Comparison of long-term results between radiotherapy after breast-conserving surgery and postmastectomy radiotherapy in stage T1-2N1M0 breast cancer. Cancer Manag Res. 2019;11:6477-6487. doi:10.2147/CMAR. S209634

28. Bartelink H. Radiotherapy to the conserved breast, chest wall, and regional nodes: is there a standard? Breast. 2003;12:475-482. doi:10.1016/S0960-9776(03)00155-3

29. Edwards-Bennett SM, Correa CR, Harris EE. Optimization of adjuvant radiation in breast conservation therapy: can we minimize without compromise? Int J Breast Cancer. 2011;2011:321304. doi:10.4061/2011/321304

30. Yang DS, Yoon WS, Chung SY, et al. Set-up uncertainty during breast radiotherapy. Image-guided radiotherapy for patients with initial extensive variation. Strahlenther Onkol. 2013;189:315-320. doi:10.1007/s00066-012-0271-4

31. Mészáros N, Major $\mathrm{T}$, Stelczer $\mathrm{G}$, et al. Implementation of image-guided intensity-modulated accelerated partial breast irradiation: three-year results of a Phase II clinical study. Strahlenther Onkol. 2017;193:70-79. doi:10.1007/s00066-016-1074-9

32. Bergom C, Prior P, Kainz K, et al. A phase I/II study piloting accelerated partial breast irradiation using CT-guided intensity modulated radiation therapy in the prone position. Radiother Oncol. 2013;108:215-219. doi:10.1016/j.radonc.2013.05.039 
33. Armenian SH, Lacchetti C, Barac A, et al. Prevention and monitoring of cardiac dysfunction in survivors of adult cancers: American Society of Clinical Oncology Clinical Practice Guideline. J Clin Oncol. 2017;35:893-911. doi:10.1200/JCO.2016.70.5400

34. Jin F, Luo HL, Zhou J, et al. Cancer risk assessment in modern radiotherapy workflow with medical big data. Cancer Manag Res. 2018;10:1665-1675. doi:10.2147/CMAR.S164980
35. Johansson S, Svensson H, Denekamp J. Dose response and latency for radiation-induced fibrosis, edema, and neuropathy in breast cancer patients. Int $J$ Radiat Oncol Biol Phys. 2002;52:1207-1219. doi:10.1016/S0360-3016(01)02743-2

\section{Publish your work in this journal}

Cancer Management and Research is an international, peer-reviewed open access journal focusing on cancer research and the optimal use of preventative and integrated treatment interventions to achieve improved outcomes, enhanced survival and quality of life for the cancer patient.
The manuscript management system is completely online and includes a very quick and fair peer-review system, which is all easy to use. Visit http://www.dovepress.com/testimonials.php to read real quotes from published authors. 